\title{
ROAD TRAFFIC INJURIES AMONG PATIENTS WHO ATTENDED THE ACCIDENT AND EMERGENCY UNIT OF THE UNIVERSITY OF MALAYA MEDICAL CENTRE, KUALA LUMPUR
}

\author{
Moe H \\ Department of Social and Preventive Medicine, Faculty of Medicine, University of Malaya, 50603 Kuala Lumpur, Malaysia
}

\begin{abstract}
:
A retrospective cross-sectional study of injury patients who attended the Accident and Emergency Unit was conducted at the University of Malaya Medical Centre. Demographic data with regards to age, sex, race, occupation and the relevant data such as type of accident, type of injury sustained and also severity seen during the month of January 2005 were selected retrospectively from medical record. The objectives were to review road traffic accidents and their severity of injuries among the patients. There were two hundred and forty-three (197 males and 46 females) patients involved: 60\% Malays, $16 \%$ Chinese, $21 \%$ Indians and 3\% other ethnic groups. Peak accidents occurred among the 21 to 30 years age group. Among the type of accidents, $65.8 \%$ involved motorbike riders, $10.3 \%$ car drivers, $8.6 \%$ pillion riders, $7.8 \%$ car passengers, $5.8 \%$ pedestrians and $1.6 \%$ were bicycle rider injuries. About $57.6 \%$ sustained minor injuries and $42.4 \%$ major injuries. There was no significant association between outcome of road traffic accidents and sex, age group and race. However, there was a significant association between type of accidents and severity of injuries $(\mathrm{p}=0.014)$. Males sustained more major injuries and motorbike accidents were the highest among road injuries. Therefore, further prevention and control with emphasis on behavioural changes, education and law enforcement may reduce the number of road traffic accidents in the future. (JUNMEC 2008; 11(1) 22-26)
\end{abstract}

KEYWORDS: Road traffic injuries, road traffic crashes, disability adjusted life years

\section{Introduction}

Road traffic accident injuries, one of the most common injuries sustained from a road traffic crash, are defined as fatal or non-fatal injuries incurred as the result of road traffic crashes. The crash is defined as a collision or incidence that may or may not lead to injury, occurring on a public road and involving at least one moving vehicle (I).

With over millions of people killed every year on the world's roads, and ten million more injured, road traffic crashes are one of the leading causes of death and the ninth leading cause of disability adjusted life years (DALYs) lost worldwide (2). In the year 2002, nearly I.2 million people worldwide died as a result of road traffic crashes. This represents an average of 3,242 persons dying each day around the world. In addition to these deaths, between 20 and 50 million people globally are estimated to be injured or disabled every year (I). In America, it has become the single greatest killer between the age of one and 44 years (2)

There are several types of road traffic accidents which include motor vehicle accidents involving drivers, motorcyclists, pillion riders and passengers in the car, cyclists and pedestrians. In Malaysia, cars are most commonly involved, followed by motorcycles, lorries and vans (3). According to the Ministry of Health $(\mathrm{MOH})$, injuries including road traffic accidents are the third cause of admission and fifth cause of death in Malaysian government hospitals and clinics (4). According to statistics produced by the Malaysian Road Safety Council, there are fourteen causes of road

Correspondence:

Moe H

Department of Social and Preventive Medicine

Faculty of Medicine

University of Malaya

50603 Kuala Lumpur, Malaysia 
accident in Malaysia. The common causes are speeding (32.8\%), careless driving (28.2\%) and careless overtaking (15.1\%). It showed that the driver's behaviour is the main cause of road accidents, contributing to $76.1 \%$ of all the causes of road accidents. Other factors are tailgating (driving too closely behind another vehicle) $(3.8 \%)$ and road condition (3\%) (5).

The objective of this study is to have an overview of the road traffic users involved in road traffic accidents and patients attended to at the Accident and Emergency Unit of the University of Malaya Medical Centre (UMMC) in January 2005. It is also aimed at identifying the sociodemographic characteristics of patients, description of the types of road traffic accidents and injuries, and the severity of outcome for further prevention and control.

\section{Material and Methods}

A retrospective cross-sectional study on patients who were attended to at the Accident and Emergency Unit of the University of Malaya Medical Centre (UMMC) due to road traffic accident injuries was conducted based on case records of their injury status and other information. This involves the patients who came to casualty before the Trauma Centre was opened at this tertiary level hospital in Malaysia. Permission to conduct this study was obtained from the relevant hospital authorities. All records of patients seen in the Emergency Department for road traffic injuries from I to 31 January 2005 were selected for this study.

From the registration number, the records were traced at the Medical Record Department of UMMC. The demographic data with regard to age, sex, race, occupation and other relevant data such as the types of accidents, types of injuries by the patients and also the severity of outcome were obtained retrospectively. There were 250 cases identified originally. However, seven cases were excluded because the records could not be traced. Finally, 243 subjects were included comprising 142 Malays, 39 Chinese, 52 Indians and 7 from other ethnic groups. All the data was processed and analysed by appropriate statistical tests using SPSS software.

\section{Results}

Among 243 patients, I57 (64.6\%) registered their occupation while 86 (35.4\%) did not. Of the registered workers, 22 (9.1\%) were professionals, 6 (2.5\%) were skilled workers, 9 (3.7\%) were semi-skilled workers, I 4 (5.8\%) were unskilled workers and 17 (7.0\%) were
Table I. Distribution of occupations of accident victims

\begin{tabular}{llc}
\hline Occupation & Frequency (\%) \\
\cline { 3 - 3 } Registered & Professional & $22(9.1 \%)$ \\
& Skilled worker & $6(2.5 \%)$ \\
& Semiskilled worker & $9(3.7 \%)$ \\
& Unskilled worker & $14(5.8 \%)$ \\
& Housewife & $17(7.0 \%)$ \\
Not registered & Student & $89(36.6 \%)$ \\
& & $86(35.4 \%)$ \\
\hline \multirow{2}{*}{ Total } & & $\mathbf{2 4 3 ( 1 0 0 \% )}$ \\
\hline
\end{tabular}

Not registered $=$ not mentioned in the registration card .

Table 2. Mode of transport among patients in January 2005

Type of accident Frequency Percentage

\begin{tabular}{lcr}
\hline Car (driver) & 25 & 10.3 \\
Car (passenger) & 19 & 7.8 \\
Motorbike (rider) & 160 & 65.8 \\
Pillion rider & 21 & 8.6 \\
Bicycle (rider) & 4 & 1.6 \\
Pedestrian & 14 & 5.8 \\
\hline Total & $\mathbf{2 4 3}$ & $\mathbf{1 0 0}$ \\
\hline
\end{tabular}

Table 3. Severity of injuries sustained during accidents by sex

\begin{tabular}{lccc}
\hline \multicolumn{4}{c}{ Severity of injury } \\
\hline Gender & Minor & Major & Total \\
Male & $112(57)$ & $85(43)$ & 197 \\
Female & $28(6 I)$ & $18(39)$ & 46 \\
\hline Total & I $40(57.6 \%)$ & I $03(42.4 \%)$ & 243 \\
\hline
\end{tabular}

housewives. The largest proportion of registered patients was students 89 (36.6\%). (Table I).

Table 2 shows the type of road traffic accidents that happened in January 2005, with accidents involving motorbike riders registering the highest number $(65.8 \%)$, followed by car drivers $(10.3 \%)$, pillion riders $(8.6 \%)$, car passengers $(7.8 \%)$, pedestrians (5.8\%) and bicycle riders ( $1.6 \%$ ).

Regarding severity of injuries sustained in January 2005, the majority of the patients were treated in the casualty and discharged and considered as minor injuries 
Table 4. Severity of injuries sustained during road traffic accident by age groups

\begin{tabular}{llcc}
\hline \multicolumn{4}{l}{ Severity of injury } \\
\hline Age group & Minor & Major & Total \\
\hline $\begin{array}{l}\text { Young } \\
\text { I-20 yrs old }\end{array}$ & $40(58)$ & $29(42)$ & 69 \\
$\begin{array}{l}\text { Adult } \\
\text { 2I-50 yrs old }\end{array}$ & $99(59)$ & $69(4 I)$ & 168 \\
$\begin{array}{l}\text { Elderly } \\
>50 \text { yrs old }\end{array}$ & I (16.7) & $5(83.3)$ & 6 \\
\hline Total & $\mathbf{1 4 0 ( 5 7 . 6 )}$ & $\mathbf{1 0 3 ( \mathbf { 4 2 . 4 ) }}$ & $\mathbf{2 4 3}$ \\
\hline
\end{tabular}

(140,57.6\%). The remaining had to be admitted to the wards for further treatment and only one patient died. These were considered as major injuries (I03, 42.4\%) (Table 3).

Severity of the road traffic injuries among patients was compared by gender. Of the 197 males, I I 2 had minor and 85 had major injuries. As for the 46 female patients, 28 of them had minor and the remaining 18 experienced major injuries (Table 3). However, statistical analysis did not show any significant difference between the sex of the patients and the severity of the road traffic injuries $\left(\chi^{2}=0.246, d f=I, p=0.62\right)$.

Severity of the road traffic injuries was compared by the age groups. Among them, the majority $(59 \%)$ occurred in the adult age group 18-60 years old with minor injuries. Out of 69 patients from the young age group, 40 (58\%) experienced minor while the other 29 (42\%) patients sustained major injuries. There were elderly patients with one minor injury while five had major injuries. The differences in severity of the road traffic injuries by age group were not significant $\left(\chi^{2}=4.242\right.$, $\mathrm{df}=2$,

Table 5. Severity of injuries sustained by ethnicity

\section{Severity of injury}

\begin{tabular}{lrrc}
\hline Age group & Minor & Major & Total \\
\hline Malay & $80(55.2)$ & $65(44.8)$ & 145 \\
Chinese & $24(6 I .5)$ & $15(38.5)$ & \multicolumn{1}{c}{39} \\
Indian & $31(59.6)$ & $21(40.4)$ & 52 \\
Others & $5(7 I .4)$ & $2(28.6)$ & 7 \\
\hline Total & I 40 (57.6) & I $03(\mathbf{4 2 . 4 )}$ & $\mathbf{2 4 3}$ \\
\hline
\end{tabular}

Others $=$ Bangladeshi, Vietnamese and Caucasian. $(\mathrm{p}=$ 0.745).
Table 6. Severity of injuries sustained in road traffic accidents by type of accidents

\begin{tabular}{lccc}
\hline \multicolumn{4}{c}{ Severity of injury } \\
\hline Age group & Minor & Major & Total \\
\hline Car & $33(75)$ & $I I(25)$ & 44 \\
Motorbike & $10 I(55.8)$ & $80(44.2)$ & $18 \mid$ \\
Bicycle & $2(50)$ & $2(50)$ & 4 \\
Pedestrian & $4(28.6)$ & $10(71.4)$ & 14 \\
\hline Total & I $40(57.6)$ & I $03(\mathbf{4 2 . 4 )}$ & $\mathbf{2 4 3}$ \\
\hline
\end{tabular}

Car $=$ Car driver and car passenger,

Motorbike $=$ Motorbike rider and pillion rider. $(p=0.014)$

$p=0.12)($ Table 4).

Severity of the road traffic injuries among patients were compared by ethnicity. Out of 243 patients, 145 were Malays. Among Malays, 80 (55.2\%) had minor while 65 (44.8\%) had major injuries. Among the 39 Chinese, 24 patients had minor and 15 patients had major injuries. Among the 52 Indians, 31 of them had minor and the remaining 21 had major injuries. Among the other ethnic groups, five patients had minor and two patients had major injuries. There was no significant difference between races and the severity of the road traffic injuries $\left(\chi^{2}=1.232, \mathrm{df}=3, \mathrm{p}=0.745\right)$ (Table 5).

Severity of the road traffic injuries were compared with the modes of transports. Of all the patients, the majority numbering 181 involved motorbikes. Among them, I0I (55.8\%) cases had minor, while 80 (44.2\%) had major injuries. This was followed by car with 44 cases. Among them, 33 had minor while II had major injuries. Accident involving bicycles comprised two patients with minor and two patients with major injuries. On the other hand, 4 of the pedestrians had minor and the remaining 10 sustained major injuries. The findings were shown in Table 6 and statistical analysis showed that there was significant difference between the type of transport and the severity of injuries $\left(\chi^{2}=10.620\right.$, $d f=3, p=0.014)$.

\section{Discussion}

This study shows that most of the road traffic injuries occurred in the age group between 21 to 30 years, followed by II to 20 years. A national study done in 1996 reported that majority of road injuries occurred among 10 to 19 years followed by 20 to 29 years. Deaths are more common among the young adults and adolescents (6). A report by the Royal Malaysian Police showed that the majority of the road traffic accidents 
were among adolescents aged between 16 to 20 years (3). This could be because the adolescents and young adults were major road users and thus prone to get injuries. There is also limited information on safety practices particularly among adolescents, in this country. This represents a great loss in the productivity among the young adult age group.

This study also revealed that most patients who attended the Accident and Emergency Unit due to road traffic accidents sustained minor injuries. Most of them had soft tissue injuries, multiple abrasion and minor lacerations. However, the figures did not show much difference between minor and major injuries. This might be because of short study period. The cases were not enough to reveal the true picture of road injuries in the area.

In almost one third of patients, the occupation was not known. One of the reasons could be because some patients were brought in by passer-by who did not know about the patients. It could also arise from incomplete data collection at the registration counter of Accident and Emergency Unit. Proper investigation and follow up are needed to overcome these problems.

There was a significant association between the mode of transport and the severity of road traffic injuries. Accidents involving motorbikes gave the largest proportion of all types of accidents. This could be due to a higher risk factor for those who ride motorcycles compared to other road users. Many motorcyclists do not use the correct lane for the motorcycles. They tend to ride the main road and weave between cars. Furthermore, young adults nowadays like to race and ride their motorcycles at high speed. This makes them more prone to accidents. Some of the motorcyclists were still students who were under age and some of them did not have driving licences. Therefore, they lacked driving skills and experience that led them to sustain more injuries. For those who were involved with car accidents, the majority $(75 \%)$ of them sustained minor injuries, but the rest sustained major injuries. The reason for this could be due to the improper or lack of use of seat belts. Seat belt effectively reduces serious injuries and death. A study done in US showed that teenage drivers and front seat passengers were likely to use seat belts compared with the older drivers (7). Another study done in New Zealand reported the seat belt usage among drivers were $91 \%$, front seat passenger $93 \%$ and rear seat passenger $40 \%$. However, some of the car users still refused to use seat belts. The reasons given for not using seat belt were driving for short distance, forgetfulness and were in a hurry. The other reason was 'not in a habit' (8). This could contribute to major injuries sustained.
In this study, it was noted that few cyclists were involved in accidents. Perhaps it is because only a small number of people use bicycles nowadays, especially in the cities like Kuala Lumpur, and they usually do not cycle on the main road. The majorities of them use bicycle for recreational activities and exercise. Pedestrians appeared to sustain major injuries. This might be because of being unprotected. Some pedestrians involved were not at fault.

There are some limitations to consider in this study. This study was done in UMMC only and similar cases from other hospitals were not included. The cases were very limited because of the short study period. Furthermore, some of the records were not available being misplaced in other area e.g. other clinics, or unable to find during the study period. In addition, the author should categorically stress on the quality of data based on the secondary data which warrants cautious interpretation including missing information and other required information not available in such data. Further information is needed to assess the outcome of the patients who survived after road traffic injuries and discharged from the UMMC.

\section{Conclusion}

This study describes types of road traffic injuries among patients who attended the Accident and Emergency Unit at UMMC in January 2005. There was a significant association between severities of injuries with types of road traffic accidents. However, there were no significant association between the outcome with sex, age and ethnicity. Many parties should play their roles in reducing the road traffic accidents and injuries. Parents can help to reduce road traffic accidents as they determine when their children are ready to get a driving license and what vehicle they can drive. Schools have a role to play by emphasising the importance of road safety, like the use of seat belts and proper driving practices to the adolescents and young adults as they will eventually become road users. Prevention and control with emphasis on behavioural changes, education and law enforcement may reduce the number of road accidents in the future.

\section{Acknowledgements}

The author wishes to thank the Accident and Emergency Unit and the Medical Record Unit of the University of Malaya Medical Centre for allowing the collection of relevant records and data to conduct this study. The data collection and part of the analysis were done by Azad Eryani who was involved in the elective programme. 


\section{References}

I. World Health Organization. Report on injuries and violence prevention: Road traffic injuries. Geneva: WHO; 2002.

2. Binder S, Runge, JW. Road Safety and Public Health: A US perspective and the global change. Traff Injury Prev 2002; 7:3-9.

3. Royal Malaysian Police. Statistical report road accident Malaysia 2002. Bukit Aman, Kuala Lumpur: Traffic Police Headquarters; 2002.

4. Ministry of Health Malaysia. Department of Public Health. Annual Report; 2004.
5. Suret S. Road safety issues in Malaysia. Symposium on Road Safety. Road Safety Department. Ministry of Transport Malaysia; 2001.

6. Ministry of Health Malaysia. Epidemiology of injury in Malaysia. Injury Prevention and Control Unit, Disease Control Division, Public Health Department, Ministry of Health Malaysia; 1997.

7. Presser DF, Williams AF, Lund AK. The effect of New York's seat belt use law on teenage drivers. Acc Anal Prev 1987; 19:73-80.

8. Begg DJ, Langley JL. Seat-belt use and related behaviours among young adults. J Safety Res 2000; 4: $211-20$. 